\title{
Biological characterization and selection criteria of adjuvant chemotherapy for early breast cancer: experience from the Italian observational NEMESI study
}

Matteo Clavarezza ${ }^{1,16^{*}}$, Giorgio Mustacchi ${ }^{2}$, Andrea Casadei Gardini ${ }^{3}$, Lucia Del Mastro ${ }^{4}$, Andrea De Matteis ${ }^{5}$, Ferdinando Riccardi ${ }^{6}$, Vincenzo Adamo ${ }^{7}$, Enrico Aitini ${ }^{8}$, Domenico Amoroso ${ }^{9}$, Paolo Marchetti ${ }^{10}$, Stefania Gori ${ }^{11}$, Francesco Carrozza ${ }^{12}$, Evaristo Maiello ${ }^{13}$, Francesco Giotta ${ }^{14}$, Davide Dondi ${ }^{15}$ and Marco Venturini ${ }^{1}$

\begin{abstract}
Background: International treatment guidelines recommend administration of adjuvant chemotherapy in early breast cancer based on clinical, prognostic and predictive parameters.

Methods: An observational study (NEMESI) was conducted in 63 Italian oncology centres in patients with early breast cancer. Age, performance status, concomitant disease, menopausal status, histology, tumor dimension (pT), axillary lymph node status $(\mathrm{pN})$, grading $(\mathrm{G})$, estrogen and progesterone receptor (ER and PgR), proliferative index (ki67 or MIB-1), human epidermal growth factor receptor 2 (HER2) and type of adjuvant treatment were recorded. The primary objective of the study was to define parameters influencing the decision to prescribe adjuvant chemotherapy and the type of chemotherapy.

Results: Data for 1894 patients were available. 69.0\% postmenopausal, 67.0\% pT1, 22.3\% pTmic/pT1a/pT1b, 61.0\% pNO, 48.7\% luminal A, 18.1\% luminal B, 16.1\% HER2 positive, 8.7\% triple negative, 8.4\% unknown. 57.8\% received adjuvant chemotherapy: $38.1 \%$ of luminal A, 67.3\% luminal B, 88.2\% HER2-positive, 97.6\% triple negative. Regimens administered: 9.1\% CMF-like, 48.8\% anthracyclines, 38.4\% anthracyclines plus taxanes, 3.7\% taxanes alone. Increasing $\mathrm{pT} / \mathrm{pN}$ and, marginally, HER2-positive were associated with the prescription of anthracyclines plus taxanes. Suboptimal schedules (CMF-like or AC/EC or FEC-75) were prescribed in 37.3\% receiving chemotherapy, even in HER2-positive and triple negative disease (36.5\% and 34.0\%, respectively).
\end{abstract}

Conclusions: This study showed an overprescription of adjuvant chemotherapy for early breast cancer, particularly referred to luminal A. pT, pN and, marginally, HER2 were the principal determinants for the choice of chemotherapy type. Suboptimal chemotherapy regimens were adopted in at least one third of HER2-positve and triple negative.

\footnotetext{
* Correspondence: matclava78@libero.it

'Ospedale Sacro Cuore Don Calabria, Negrar, Verona, Italy

${ }^{16}$ Oncology Department, Ospedale Sacro Cuore Don Calabria Via Don A. Sempreboni 5, 37024 Negrar, Verona, Italy

Full list of author information is available at the end of the article
} 


\section{Background}

Breast cancer is the most common malignancy in women in Italy and its incidence is similar to the data from other tumor registry of other countries such as NORDCAN [1], SEER [2], UK [3]. Breast cancer incidence increased until 2000. From 2003 breast cancer incidence in USA is little decreasing for the reduced administration of hormonal replacement therapy $[4,5]$, while in Italy from 2000 incidence is stable above all because of completed extension of mammographic screening [6-8]. In Italy breast cancer incidence vary according to geographic location. In fact, it is 115 cases per 100,000 women (45000 new cases each year), consisting of $29 \%$ of all new diagnosis of malignancies, with significant differences between North, Centre and South Italy: 123, 103 and 87 new cases are diagnosed each year per 100,000 women, respectively [9]. This difference is due to the different extension of mammographic screening and different risk factors for breast cancer, above all the different life-styles, with North Italy with a life-style more similar to North Europe and United States compared to South Italy.

Breast cancer causes more than 11,000 deaths each year in Italy, 24.2 cases per 100,000 women/year, with no relevant difference between North, Centre and South Italy $(24.8,21.1,24.7$ deaths for breast cancer per 100000 women/year), even if 5-year overall survival is between $85 \%$ and $87 \%$ in North and Centre Italy, compared to $81 \%$ of South Italy [9]. This difference is probably due to the different possibility to access to screening program [10].

Optimal management of patients with early breast cancer involving integrated treatments encompassing surgery, radiotherapy and systemic therapy had led, together to breast cancer screening, to mortality reduction [11]. Tumor stage, histological grading, estrogen and progesterone receptor (ER and $\mathrm{PgR}$ ), proliferative index and human epidermal growth factor receptor 2 (HER2) aid in tumor evaluation and often dictate the choice of systemic treatment. Evidence-based international treatment guidelines including those of the NCCN (National Comprehensive Cancer Network) [12], the National Cancer Institute (NCI) [13] and the St. Gallen Consensus Report [14] recommend using adjuvant therapy for patients with early breast cancer. In particular adjuvant chemotherapy is not recommended for endocrine-sensitive breast cancer (ER-positive, low proliferative index and HER2 negative) with low recurrence risk. On the contrary, it is particularly indicated in at least one of the following biological conditions: ER-negative, HER2 positive, high proliferative index $(>30 \%)$, grading 3 . It remains unclear which is the role of adjuvant chemotherapy in endocrine sensitive breast cancer with intermediate recurrence risk (tumor diameter of $2 \mathrm{~cm}$ or more or node- positive from one to three lymph nodes), grading 2, proliferation index below 30\%.

The aim of this retrospective observational study is to analyze factors influencing the choice for adjuvant chemotherapy, type of chemotherapy and schedules of chemotherapy in patients with early breast cancer in order to improve knowledge about the therapeutic management of early breast cancer in Italy and verify the adherence to international guidelines.

\section{Methods}

\section{Study design}

NEMESI is a retrospective observational study conducted at oncology unit throughout Northern, Central and Southern Italy. Institution types included IRCCS (Istituto di Ricovero e Cura a Carattere Scientifico), public hospital and private hospitals with oncology unit, public and private university hospitals. Centres were selected from the 386 censed centres (complex oncology units or simple oncology units with or without breast units) reported in the White Book of the Italian Association of Medical Oncology (AIOM 2006) in order to covering the whole spectrum of treatment of breastcancer patients [15]. Centres were selected to represent Italian scenario on the basis of three criteria. The first was a geographic criteria: each area (North, Center and South-Islands) was to be proportional to the centres included in Libro Bianco (North Italy: 33 participating centres of 179 censed centres of Libro Bianco, which represent $52.4 \%$ of all centres of the study and $46.4 \%$ of all centres of Libro Bianco, respectively; Central Italy: 11 participating centres of 92 censed centres of Libro Bianco, which represent $17.5 \%$ of all centres of the study and $23.8 \%$ of all centres of Libro Bianco, respectively; Southern Italy and Islands: 19 participating centres of 108 of all centres of Libro Bianco, which means 30.1\% of all centres of the study and $29.8 \%$ of all centres of Libro Bianco, respectively). The second selection criterion was that each type of Institution must to be rapresentated proportionally to Libro Bianco (7.5\% of Private Hospital, $7.5 \%$ of IRCCS, $70 \%$ of Public or Private Hospital with Oncology Unit and 15\% of public and Private University Hospital). The third criterion was to select centres with at least 120 new cases attending each oncologic centre in 2008 in order to ensure anonymity as required by Italian regulations governing observational studies (AIFA document, dated 30 March 2008).

Patients were eligible for the study if they met the following criteria: women, age $\geq 18$ years; histological diagnosis of stage I, II or III breast cancer according to the tumor, node, metastasis (TNM) classification devised by the American Joint Committee on Cancer (AJCC) version VI [16]; undergone surgery; prescribed and received at least one cycle of adjuvant chemotherapy and/or 
prescribed adjuvant hormonal therapy; availability of data for the following parameters: tumor dimension $(\mathrm{pT})$, axillary lymph node status $(\mathrm{pN})$, grading $(\mathrm{G})$, ER and PgR, HER2, and proliferative index (Ki67 or MIB-1). However, patients with lacking of one or more of these parameters were eligible and included in the analysis in order to obtain a real photograph of data available for the process choice of adjuvant chemotherapy. Candidates for adjuvant therapy with trastuzumab and/or radiotherapy on the residual breast or thoracic wall, regional supraclavear, internal breast lymph node stations were also eligible. Exclusion criteria were: use of neo-adjuvant therapy, diagnosis of metastatic breast cancer (stage IV) or in-situ carcinoma. Data were retrieved retrospectively by each site from the patients' clinical records.

The protocol was reviewed by the independent ethics committee of the coordinating center. Notification of the study was also sent to the ethics committees of each participating center, as required by Italian regulations governing observational studies (AIFA document, dated 30 March 2008). The protocol complied with the Declaration of Helsinki.

\section{Sample size determination and data collection}

Each center was requested to collect, by December 2009, data from a minimum of 10 and a maximum of 30 patients with breast cancer attending the center between 1 January 2008 and 30 June 2008. Each center had two particular requests in the selection of cases. First: data were collected by each center in a consecutive manner from a chronological point of view for patients attending oncologic units in the indicated period in order to exclude any selection bias. Second: each center had the request to collect data from at least $33 \%$ of patients receiving adjuvant chemotherapy. This particular inclusion criterion was necessary in order to obtain a sufficient number of patients receiving adjuvant chemotherapy in order to analyze, from a statistical point of view, parameters involving the choice to administer adjuvant chemotherapy. Data were collected on an electronic clinical report form and were submitted for automatic checks to assess completeness, correctness and internal coherence.

\section{Statistical analysis}

Continuous variables were summarized using descriptive statistics, including number of subjects, mean, standard deviation, median, minimum, 25th percentile, 75th percentile and maximum. For categorical variables, summaries included counts of subjects and percentages. Multivariate logistic regression analysis was used to assess the relationship between clinical and demographic variables, choice of adjuvant chemotherapy, the regimen administered, and the following covariates: patient age, menopausal status, previous breast cancer history, ECOG performance status, surgery type, tumor stage, ER, PgR, HER2 and proliferative index. ER/PgR status and proliferative index were included in the model as categorical variables as well as continuous variables. A stepwise procedure was used with a significance level of $\mathrm{p}=0.05$ to retain variables in the model. Odds ratio (OR) estimates and their 95\% confidence intervals (CIs) were also calculated. Two-sided 95\% CIs for proportions and means are reported where applicable. The Statistical Analysis System version 9.1.3 for Windows (SAS Institute Inc., Cary, NC, USA) was used for statistical analysis.

\section{Results}

Demographic and breast cancer biological characteristics

Data were collected from a total of 1894 patients in the 63 participating Italian oncology centres. Demographic data are summarized in Table 1. Tumor characteristics and biological classification based on ER, PgR, Ki67 or MIB, HER2 are summarized in Table 2.

The median tumor diameter was $1.7 \mathrm{~cm}$ (range: 0.1 to $35.0 \mathrm{~cm}$ ). Overall $22.3 \%$ of tumors were $\leq 1.0 \mathrm{~cm}$ in diameter; pT1c was the more frequent breast cancer pT stage: $44.7 \%$. The median number of involved lymph nodes was 1 (range: 0 to 47 ), 61.0\% were pN0 and 9.9\% pN2 or $\mathrm{pN} 3$.

\section{Table 1 Demographic data of valuable patients}

\begin{tabular}{ll}
\hline Demographic characteristics & $\mathbf{n}(\%)$ \\
\hline Total & $1894(100)$ \\
\hline Median age range (years) & $30(1.6)$ \\
\hline$\geq 18-34$ & $469(24.8)$ \\
\hline$\geq 50-49$ & $984(51.9)$ \\
\hline$\geq 70$ & $411(21.7)$ \\
\hline ECOG ${ }^{*}$ Performance Status & \\
\hline 0 & $1661(87.7)$ \\
\hline 1 & $179(9.5)$ \\
\hline 2 & $25(1.3)$ \\
\hline 3 & $6(0.3)$ \\
\hline Missing & $23(1.2)$ \\
\hline Menopausal status & \\
\hline Premenopausal & $566(29.9)$ \\
\hline Postmenopausal & $1802(95.2)$ \\
\hline Missing & $6(0.3)$ \\
\hline Second diagnosis of breast cancer & $21(1.1)$ \\
\hline Not reported & \\
\hline
\end{tabular}

* ECOG = Eastern Cooperative Oncology Group. 
Table 2 Tumor characteristics of evaluable patients

\begin{tabular}{|c|c|c|c|}
\hline $\begin{array}{l}\text { Disease characteristic } \\
(n=1894)\end{array}$ & Total, n (\%) & $\mathrm{CT}, \mathrm{n}(\%)$ & No $\mathrm{CT}, \mathrm{n}(\%)$ \\
\hline \multicolumn{4}{|l|}{ Tumor dimensions (pT) } \\
\hline • pT1mic-pT1a-pT1b & $422(22.3 \%)$ & $132(31.3 \%)$ & $290(68.7 \%)$ \\
\hline -pT1c & $846(44.7 \%)$ & $515(60.9 \%)$ & $331(39.1 \%)$ \\
\hline - pT2-pT3-pT4b & $626(33.0 \%)$ & $448(71.6 \%)$ & $178(28.4 \%)$ \\
\hline \multicolumn{4}{|c|}{ Axillary lymph node status (pN) } \\
\hline - pNO & $1155(61.0 \%)$ & $502(43.5 \%)$ & $653(56.5 \%)$ \\
\hline$\cdot \mathrm{pN1}$ & $551(29.1 \%)$ & $422(76.6 \%)$ & $129(23.4 \%)$ \\
\hline$\cdot \mathrm{pN2}$ & $119(6.3 \%)$ & $106(89.1 \%)$ & $13(10.9 \%)$ \\
\hline - $\mathrm{pN} 3$ & $69(3.6 \%)$ & $65(94.2 \%)$ & $4(5.8 \%)$ \\
\hline \multicolumn{4}{|c|}{ Estrogen and Progesterone Receptor (ER/PgR) } \\
\hline - ER or PgR-positive ( $\geq 1 \%)$ & $1619(85.5 \%)$ & $829(51.2 \%)$ & $790(48.8 \%)$ \\
\hline - ER and PgR 0\% & $274(14.5 \%)$ & $266(97.1 \%)$ & $8(2.9 \%)$ \\
\hline - Unknown & $1(0.1 \%)$ & $0(0.0 \%)$ & $1(100 \%)$ \\
\hline \multicolumn{4}{|c|}{ Proliferative index (Ki67 or MIB-1) } \\
\hline - Low ( $\leq 20 \%)$ & $1150(60.7 \%)$ & 499 (43.4\%) & $651(56.6 \%)$ \\
\hline - High (>20\%) & $691(36.5 \%)$ & $562(81.3 \%)$ & $129(18.7 \%)$ \\
\hline - Unknown & $53(2.8 \%)$ & $34(64.2 \%)$ & 19 (35.8\%) \\
\hline \multicolumn{4}{|l|}{ HER2 } \\
\hline - Positive & 305 (16.1\%) & $269(88.2 \%)$ & $36(11.8 \%)$ \\
\hline - Negative & $1463(77.2 \%)$ & $761(52.0 \%)$ & $702(48.0 \%)$ \\
\hline - Unknown & $126(6.7 \%)$ & $65(51.6 \%)$ & $61(48.4 \%)$ \\
\hline \multicolumn{4}{|l|}{ Biological type } \\
\hline - Luminal A & $923(48.7 \%)$ & 352 (38.1\%) & $571(61.9 \%)$ \\
\hline - Luminal B & $342(18.1 \%)$ & $230(67.3 \%)$ & $112(32.7 \%)$ \\
\hline - HER2 & $305(16.1 \%)$ & $269(88.2 \%)$ & $36(11.8 \%)$ \\
\hline - Triple negative & 165 (8.7\%) & $161(97.6 \%)$ & $4(2.4 \%)$ \\
\hline - Unknown & 159 (8.4\%) & $83(52.2 \%)$ & $76(47.8 \%)$ \\
\hline
\end{tabular}

Luminal A: ER or PgR $\geq 1 \%$ and proliferative index $\leq 20 \%$ and HER2-negative. Luminal B: ER or $\mathrm{PgR} \geq 1 \%$ and proliferative index $>20 \%$ and HER2-negative. HER2-positive: HER2-positive (IHC 3+, or IHC 2+ with HER2 amplified, HER2 amplified independently from $I H C$ ) independently from the values of ER, PgR, proliferative index.

Triple negative: ER and PgR both $0 \%$ and HER2 negative independently from the proliferative index.

With respect to tumor biological characteristics, ER was $\geq 10 \%$ in $82.7 \%$, ER $\geq 1 \%$ in $84.9 \%$. When also considering PgR, ER or PgR were $\geq 1 \%$ in $85.5 \%$, ER or PgR $\geq 10 \%$ in $83.5 \%$, ER and PgR both $<10 \%$ in $16.4 \%$, ER and PgR both $0 \%$ in $14.5 \%$.

HER2 was positive in $16.1 \%$ of study population, negative in $77.2 \%$, unknown in $6.7 \%$. According to immunohistochemistry, 13.5\% were HER2 3+, 11.6\% HER2 2+, 20.5\% HER2 1+ and 47.8\% HER2 0; an amplification test (FISH, SISH, or CISH) was performed in $22.6 \%$ cases. $86.8 \%$ HER2 2+ were analyzed with amplification test, of which 26.3\% HER2 resulted as amplified.

Proliferative index was known in 97.2\%. Among these patients, proliferative index was determined with ki67 in $67.2 \%$ and with MIB-1 in $32.8 \%$. Ki67 or MIB-1 was $\leq 20 \%$ in $62.5 \%$, from $21 \%$ to $30 \%$ in $16.3 \%$, $>30 \%$ in $21.2 \%$ cases. Considering different cut-off values, $\leq 14 \%$ in $42.5 \%,>14 \%$ in $57.5 \%$.

\section{Factors affecting choice of adjuvant chemotherapy and type of chemotherapy}

$57.8 \%(\mathrm{n}=1095)$ of the study population received adjuvant chemotherapy. A summary of adjuvant chemotherapy type and the administration schedules are listed in Table 3. Table 4 presents factors associated with chemotherapy prescription.

Age was a strong determinant for chemotherapy prescription. Overall, there were no differences in the chemotherapy type prescribed according to age, although use of CMF-like regimen was more common among patients aged $\geq 70$ years. While CMF-like therapy was prescribed in $9.1 \%$ of the overall population receiving adjuvant chemotherapy, the probability increased to $27.0 \%$ in patients aged $\geq 70$ years; however, the difference was not statistically significant due to low numbers.

Menopausal status influenced the decision to use adjuvant chemotherapy: $74.9 \%$ of premenopausal and $50.3 \%$ of postmenopausal patients received adjuvant chemotherapy, respectively (OR: 2.95, CI95\%: 2.37-3.67, p $<0.0001)$. Premenopausal patients were more often treated with adjuvant anthracyclines, with or without taxanes, than postmenopausal patients $(92.7 \%$ versus $83.7 \%$ : $\mathrm{OR}=2.46$, CI95\% $=1.62-3.75, \mathrm{p}<0.0001)$. This difference was not significant considering anthracyclines alone: $49.8 \%$ versus $48.5 \%$, respectively $(p=0.68)$, but was significant for anthracyclines plus taxanes: $42.9 \%$ versus $35.3 \%$, respectively $(\mathrm{OR}=1.38, \mathrm{CI} 95 \%=1.08-1.77$, $\mathrm{p}=0.011$.

Tumor stage at first diagnosis greatly influenced the decision to use adjuvant chemotherapy as shown in Table 4. The pT category influenced the type of chemotherapy administered: the use of CMF-like therapy decreased from $13.6 \%$ of $\mathrm{pT} 1 \mathrm{mic} / \mathrm{pT} 1 \mathrm{a} / \mathrm{pT} 1 \mathrm{~b}$ to $9.9 \%$ of pT1c and to $6.9 \%$ of $\mathrm{pT} 2 / \mathrm{pT} 3 / \mathrm{pT} 4 \mathrm{~b}$ (pT1mic/pT1a/ pT1b versus pT2/pT3/pT4b: OR $=2.12, \mathrm{CI} 95 \%=1.15-$ 3.94; pT1c versus pT2/pT3/pT4b: OR $=1.48, \mathrm{CI} 95 \%=$ 0.93-2.36, $\mathrm{p}=0.047$ ) At the same time anthracyclines plus taxanes increased from $25.8 \%$ of $\mathrm{pT} 1 \mathrm{mic} / \mathrm{pT} 1 \mathrm{a} /$ pT1b to $34.6 \%$ of pT 1 c and to $46.4 \%$ of pT2/pT3/pT4b (pT2/pT3/pT4b versus pT1mic/pT1a/pT1b: OR = 2.50, CI95\% $=1.62-3.85 ; \quad$ pT1c versus $\mathrm{pT} 1 \mathrm{mic} / \mathrm{pT} 1 \mathrm{a} / \mathrm{pT} 1 \mathrm{~b}$ : $\mathrm{OR}=1.52, \quad \mathrm{CI} 95 \%=0.99-2.34, \mathrm{p}<0.0001)$. The use of anthracyclines alone decreased from $\mathrm{pT} 1 \mathrm{mic} / \mathrm{pT} 1 \mathrm{a} / \mathrm{pT} 1 \mathrm{~b}$ to pT1c (58.3\% and 50.9\%, respectively) and to pT2/ pT3/pT4b (43.5\%) (pT1mic/pT1a/pT1b versus pT2/ pT3/pT4b: OR $=1.82$ CI95\% $=1.23-2.69 ;$ pT1c versus pT2/pT3/pT4b: OR = 1.34 CI95\% = 1.04-1.73; p = 0.005).

A correlation was also seen between $\mathrm{pN}$ staging and higher rates of adjuvant chemotherapy prescription. 
Table 3 Type and schedules of adjuvant chemotherapy prescribed $(n=1095)$

\begin{tabular}{|c|c|}
\hline Type of chemotherapy & N (\%) \\
\hline CMF-like & $100(9.1)$ \\
\hline - Anthracyclines alone (without Taxanes) & $534(48.8)$ \\
\hline - Anthracyclines plus Taxanes & $420(38.4)$ \\
\hline - Taxanes alone (without Anthracyclines) & $41(3.7)$ \\
\hline \multicolumn{2}{|l|}{ Type of Taxane } \\
\hline - Docetaxel & $359(32.8)$ \\
\hline - Paclitaxel & $102(9.3)$ \\
\hline \multicolumn{2}{|l|}{ Main chemotherapeutic schedules administered } \\
\hline - Oral classical CMF 6 cycles & $24(2.2)$ \\
\hline - CMF 6 cycles iv day 1 and 8 q28d & $53(4.8)$ \\
\hline - CMF 6 cycles iv day 1 q21d & $9(0.8)$ \\
\hline - CMF 3-4 cycles iv day 1 and 8 q28d & $11(1.0)$ \\
\hline - AC 4 cycles & $89(8.1)$ \\
\hline - AC 6 cycles & $27(2.5)$ \\
\hline - $\mathrm{E}_{90} \mathrm{C} 4$ cycles & $56(5.1)$ \\
\hline - $\mathrm{E}_{75} \mathrm{C} 4$ cycles & $9(0.8)$ \\
\hline - $\mathrm{FE}_{75} \mathrm{C} 6$ cycles & $131(12.0)$ \\
\hline - $\mathrm{FE}_{90} \mathrm{C} 6$ cycles & $95(8.7)$ \\
\hline - $\mathrm{FE}_{100} \mathrm{C} 6$ cycles & $29(2.6)$ \\
\hline - FAC 6 cycles & $8(0.7)$ \\
\hline - Canadian CEF 6 cycles & $16(1.5)$ \\
\hline - Epidoxorubicin 4 cycles - CMF 4 cycles & $5(0.5)$ \\
\hline - AC 4 cycles - CMF 3 cycles & $15(1.4)$ \\
\hline - FEC 3 cycles - Docetaxel 3 cycles & $118(10.8)$ \\
\hline - AC/EC 4 cycles - Docetaxel 4 cycles & $127(11.6)$ \\
\hline - TAC 6 cycles + G-CSF & $29(2.7)$ \\
\hline - AC/EC 4 cycles - Paclitaxel q3wks 4 cycles & $39(3.6)$ \\
\hline - FEC/EC 4 cycles - weekly Paclitaxel x 12 & $43(3.9)$ \\
\hline - A/EP 4 cycles - CMF 4 cycles & $7(0.6)$ \\
\hline - ET 6 cycles & $12(1.1)$ \\
\hline - TC 4 cycles & $19(1.7)$ \\
\hline - TC 6 cycles & $8(0.7)$ \\
\hline - Others & $116(10.6)$ \\
\hline
\end{tabular}

Anthracyclines plus taxanes use increased with $\mathrm{pN}$ status: $19.9 \%$ of pN0 patients with prescription of adjuvant chemotherapy received anthracyclines plus taxanes, increasing to $45.0 \%$ for $\mathrm{pN} 1$ patients and $76.0 \%$ in $\mathrm{pN} 2 /$ $\mathrm{pN} 3$ patients ( $\mathrm{pN} 1$ versus $\mathrm{pN} 0: \mathrm{OR}=3.29, \mathrm{CI} 95 \%=2.46$ 4.41 ; $\mathrm{pN} 2-\mathrm{pN} 3$ versus $\mathrm{pNO}$ : $\mathrm{OR}=12.75$, CI95\% $=8.43$ 19.28; $\mathrm{p}<0.0001)$. At the same time the use of CMF-like regimens decreased with higher $\mathrm{pN}: 13.3 \%$ of $\mathrm{pN} 0$ patients compared to $5.6 \%$ of lymph-node positive (pN1pN2-pN3 $) \quad(\mathrm{OR}=2.61, \quad \mathrm{CI} 95 \%=1.69-4.04, \quad \mathrm{p}<0.0001)$. The use of anthracyclines alone decreased from $63.7 \%$ of $\mathrm{pN} 0$, to $44.8 \%$ of $\mathrm{pN} 1$ and to $14.6 \%$ of $\mathrm{pN} 2-\mathrm{pN} 3$ (pN0
Table 4 Summary of the results of the multivariate logistic model analysis that evaluated the probability of being treated with adjuvant chemotherapy $(n=1894)$

\begin{tabular}{lll}
\hline Variable & OR $(\mathbf{9 5} \% \mathbf{C l})$ & p value \\
\hline Age range (years) & 1 & $<0.0001$ \\
\hline$\geq 70$ & $16.3(10.4-25.5)$ & \\
\hline$\geq 50-69$ & $46.8(27.5-79.5)$ & \\
\hline$\geq 35-49$ & $553\left(\mathrm{NE}^{*}\right)$ & $<0.0001$ \\
\hline$\geq 18-34$ & & \\
\hline pT & 1 & \\
\hline pT1mic/pT1a/pT1b & $3.3(2.2-4.8)$ & $<0.0001$ \\
\hline pT1c & $6.5(4.2-10.2)$ & \\
\hline pT2/pT3/pT4 & & \\
\hline pN & 1 & $<0.0001$ \\
\hline pN0 & $7.6(5.4-10.7)$ & \\
\hline pN1 & $45.9(17.9-117.9)$ & \\
\hline pN2 & $28.2(8.1-97.9)$ & \\
\hline pN3 & & \\
\hline Tumor grading & 1 & \\
\hline G1 & $2.8(1.7-4.6)$ & \\
\hline G2 & $7.2(4.1-12.7)$ & \\
\hline G3 & $10.3(6.1-17.6)$ & \\
\hline Estrogen receptor & $4.5(0.6-31.9)$ & \\
\hline Positive & 1 & \\
\hline Negative & & \\
\hline Biological type & & \\
\hline Luminal A & & \\
\hline Luminal B & & \\
\hline HER2 & & \\
\hline Triple negative & & \\
\hline
\end{tabular}

* Cl not calculable due to the small sample size.

versus $\mathrm{pN} 2-\mathrm{pN} 3: \mathrm{OR}=10.26, \mathrm{CI} 95 \%=6.47-16.28 ; \mathrm{pN} 1$ versus $\quad \mathrm{pN} 2-\mathrm{pN} 3: \quad \mathrm{OR}=4.74, \quad \mathrm{CI} 95 \%=2.97-7.54$, $\mathrm{p}<0.0001)$.

Combining pathological stage (IA, IB, II, III) with biological characteristics of breast cancer (luminal A, luminal B, HER2, triple negative) (Table 5) we found that decision for prescribing adjuvant chemotherapy is conditioned by both variables. Increasing pathological stage is associated with more administration of adjuvant chemotherapy independently by biological subtype. In particular, in luminal A $28.6 \%$ of patients with pT1 and pN0 and $56.2 \%$ in stage II received adjuvant chemotherapy. Compared to luminal A disease, luminal B received chemotherapy more frequently; stage IA: $30.3 \%$ versus $6.0 \%(\mathrm{OR}=6.78,95 \% \mathrm{CI}=2.64-17.43, \mathrm{p}<0.0001)$; stage IB: $50.6 \%$ versus $22.6(\mathrm{OR}=3.50,95 \% \mathrm{CI}=2.10-5.84, \mathrm{p}$ $<0.0001)$; stage II: $76.0 \%$ versus $56.2 \%(\mathrm{OR}=2.47,95 \%$ $\mathrm{CI}=1.65-3.71, \mathrm{p}<0.0001)$; stage III: $90.2 \%$ versus $81.0 \%$ $(\mathrm{p}=0.16)$. 
Table 5 Prescription of adjuvant chemotherapy according to biological type and stage. Chi square test was significant ( $p<0.0001)$ for each biological subtype

\begin{tabular}{|c|c|c|c|c|c|c|c|c|}
\hline \multirow[t]{2}{*}{ Stage } & \multicolumn{2}{|l|}{ Luminal A } & \multicolumn{2}{|l|}{ Luminal B } & \multicolumn{2}{|l|}{ HER2 } & \multicolumn{2}{|l|}{ Triple Negative } \\
\hline & CT yes, N (\%) & $\overline{C T}$ no, N (\%) & CT yes, $\mathrm{N}(\%)$ & $\overline{C T}$ no, N (\%) & CT yes, N (\%) & $\overline{C T}$ no, N (\%) & CT yes, N (\%) & CT no, N(\%) \\
\hline $\mathrm{A}^{*}$ & $12(6.0 \%)$ & 187 (94.0\%) & $10(30.3 \%)$ & $23(69.7 \%)$ & $25(64.1 \%)$ & $14(35.9 \%)$ & $17(81.0 \%)$ & $4(19.0 \%)$ \\
\hline $\mathrm{IB}^{* *}$ & $59(22.6 \%)$ & $202(77.4 \%)$ & $44(50.6 \%)$ & $43(49.4 \%)$ & 77 (88.5\%) & $10(11.5 \%)$ & $56(100 \%)$ & $0(0 \%)$ \\
\hline$\|^{* * * *}$ & $213(56.2 \%)$ & $166(43.8 \%)$ & $130(76.0 \%)$ & $41(24.0 \%)$ & $122(93.1 \%)$ & $9(6.9 \%)$ & 75 (100\%) & $0(0 \%)$ \\
\hline$\|1\| * * * *$ & $68(81.0 \%)$ & 16 (19.0\%) & $46(90.2 \%)$ & $5(9.8 \%)$ & 45 (93.8\%) & $3(6.3 \%)$ & $13(100 \%)$ & $0(0 \%)$ \\
\hline Total & 352 (38.1\%) & $571(61.9 \%)$ & $230(67.3 \%)$ & $112(32.7 \%)$ & 269 (88.2\%) & $36(11.8 \%)$ & $161(97.6 \%)$ & $4(2.4 \%)$ \\
\hline
\end{tabular}

* Stage IA: pT1mic/pT1a/pT1b and pN0 ** Stage IB: pT1c and pN0 *** Stage Il: pT1 and pN1, pT2/pT3 and pN0, pT2 and pN1 *** Stage III: all pN2, all pN3, all pT4, pT3 and pN1.

Patients with ER 0\% and PgR 0\% received adjuvant chemotherapy more often compared to patients with ER or $\operatorname{PgR} \geq 1 \%$ ( $97.1 \%$ versus $52.1 \%$, respectively; $\mathrm{OR}=$ $31.69, \mathrm{CI} 95 \%=15.58-64.44, \mathrm{p}<0.0001)$. There were no differences in the type of adjuvant chemotherapy with respect to $\mathrm{ER} / \operatorname{PgR}$ status: CMF-like therapy was prescribed in $9.8 \%$ and $8.9 \%$ in ER and PgR 0\% and ER or $\operatorname{PgR} \geq 1 \%(\mathrm{p}=0.67)$, respectively; anthracyclines without taxanes: $50.4 \%$ and $48.3 \%$, respectively $(\mathrm{p}=0.55)$; anthracyclines plus taxanes: $36.1 \%$ and $39.1 \%$, respectively $(\mathrm{p}=0.38)$; taxanes alone: $3.8 \%$ and $3.7 \%$, respectively $(\mathrm{p}=0.99)$. Between triple negative, $97.6 \%$ was treated with adjuvant chemotherapy: $81.0 \%$ stage IA compared to $100 \%$ of stage IB, II, III (Table 5).

$64.1 \%$ of patients with HER2-positive disease received adjuvant chemotherapy with a tumor diameter until $1 \mathrm{~cm}$ of diameter (stage IA). In HER2 disease stage IB + II + III $90.7 \%$ of HER2-positive breast cancer patients received adjuvant chemotherapy (HER2 stage IB + II + III versus HER2 stage IA: $\mathrm{OR}=6.21, \mathrm{CI} 95 \%=2.83-13.64, \mathrm{p}$ $<0.0001)$. In particular, in stage IA HER2-positive disease, $85.7 \%$ of hormonal receptors negative versus $52.0 \%$ of hormonal receptor positive received adjuvant chemotherapy.

HER2 status determined the choice of a regimen containing anthracyclines (with or without taxanes): $94.4 \%$ HER2-positive cases versus $85.0 \%$ HER2-negative (OR = 2.98, CI95\% $=1.71-5.21, \mathrm{p}=0.0001)$. This data must be particularly applied for regimens with anthracyclines plus taxanes $(43.5 \%$ versus $36.6 \%$, respectively: OR= $1.33, \mathrm{CI} 95 \%=1.01-1.76, \mathrm{p}=0.048)$ but not for regimens containing anthracyclines alone without taxanes $(50.9 \%$ versus $48.4 \%$, respectively, $\mathrm{p}=0.47$ ).

Analyzing HER2 as compared to other biological subtype (Table 6), prescription of CMF was constant between luminal A (11.4\%), luminal B (7.8\%) and triple-negative (10.6\%), while it was little decreasing in HER2-positive disease (4.1\%) (luminal $\mathrm{A}+\mathrm{B}+$ triple negative versus HER2: OR 2.63 CI95\%: 1.38-5.04, $\mathrm{p}=0.004)$. At the same time there is an increasing use of anthracyclines and taxanes in HER2-positive disease (43.5\%) versus luminal A (36.6\%), luminal B (37.0\%), triple negative (36.6\%). This difference was borderline significant (HER2+ versus luminal $\mathrm{A}+\mathrm{B}+$ triple negative; $\mathrm{p}=0.06$ ).

Combining pathological stage with biological characteristics (Table 7) we noted that administration of anthracyclines and taxanes increased with increasing pathological stage independently from biological subtype. At the same time the administration of anthracyclines alone decreases with increasing pathological stage.

\section{Discussions}

The results of this observational study, conducted throughout oncologic centres of Northern, Central and Southern Italy, is representative of Italy with respect to the choice of adjuvant chemotherapy for breast cancer.

The first important consideration is about demography and biology of breast cancer of this population study. In fact, most patients (85.5\%) had ER or PgR-positive ( $\geq 1 \%)$ breast cancer, while only $14.5 \%$ had both ER and PgR $0 \%$. Triple negative cases were $8.7 \%, 16.1 \%$ HER2-positive independently from hormonal receptors status. These results are probably influenced by a high proportion of postmenopausal patients (nearly 70\%) and by those aged $\geq 70$ years ( $21.7 \%$ of the population study). In the previous reported observational study conducted by Cazzaniga et al. between 2000 and 2004 [17], elderly patients were $18.5 \%$, despite the biological characteristics being similar to this study.

Table 6 Type of chemotherapy prescribed according to biological type

\begin{tabular}{lcccr}
\hline $\begin{array}{l}\text { Type of } \\
\text { chemotherapy }\end{array}$ & Luminal A & Luminal B & HER2 & $\begin{array}{l}\text { Triple } \\
\text { Negative }\end{array}$ \\
\hline CMF & $40(11.4 \%)$ & $18(7.8 \%)$ & $11(4.1 \%)$ & $17(10.6 \%)$ \\
\hline Anthracyclines & $169(48.0 \%)$ & $116(50.4 \%)$ & $137(50.9 \%)$ & $76(47.2 \%)$ \\
\hline $\begin{array}{l}\text { Anthracyclines- } \\
\text { Taxanes }\end{array}$ & $129(36.6 \%)$ & $85(37.0 \%)$ & $117(43.5 \%)$ & $59(36.6 \%)$ \\
\hline Taxanes & $14(4.0 \%)$ & $11(4.8 \%)$ & $4(1.5 \%)$ & $9(5.6 \%)$ \\
\hline Total & $352(100 \%)$ & $230(100 \%)$ & $269(100 \%)$ & $161(100 \%)$ \\
\hline
\end{tabular}


Table 7 Prescription of the type of chemotherapy based on pathological stage and biology

\begin{tabular}{|c|c|c|c|c|}
\hline Stage & CMF-like & Anthracyclines & $\begin{array}{l}\text { Anthracyclines } \\
+ \text { Taxanes }\end{array}$ & Taxanes \\
\hline \multicolumn{5}{|c|}{ Luminal A } \\
\hline$\overline{\mid A^{*}}$ & $3(25.0 \%)$ & $8(66.7 \%)$ & $0(0 \%)$ & $1(8.3 \%)$ \\
\hline $\mathrm{IB}^{* *}$ & $16(27.1 \%)$ & $36(61.0 \%)$ & $7(11.9 \%)$ & $0(0 \%)$ \\
\hline$\|^{* * * *}$ & $16(7.5 \%)$ & $113(53.1 \%)$ & 75 (35.2\%) & $9(4.2 \%)$ \\
\hline\|\|$^{* * * *}$ & $5(7.4 \%)$ & $12(17.6 \%)$ & 47 (69.1\%) & $4(5.9 \%)$ \\
\hline Total & $40(11.4 \%)$ & 169 (48.0\%) & $129(36.6 \%)$ & $14(4.0 \%)$ \\
\hline \multicolumn{5}{|c|}{ Luminal B } \\
\hline$\overline{A^{*}}$ & $1(10.0 \%)$ & $9(66.7 \%)$ & $0(0 \%)$ & $0(0 \%)$ \\
\hline $\mathrm{IB}^{* *}$ & 7 (15.9\%) & 31 (61.0\%) & $7(11.4 \%)$ & $1(2.3 \%)$ \\
\hline$\|^{* * *}$ & $10(7.7 \%)$ & $67(53.1 \%)$ & $44(33.8 \%)$ & $9(6.9 \%)$ \\
\hline\|\|$^{* * * *}$ & $0(0 \%)$ & $9(17.6 \%)$ & $36(78.3 \%)$ & $1(2.2 \%)$ \\
\hline Total & $18(7.8 \%)$ & $116(50.4 \%)$ & $85(37.0 \%)$ & $11(4.8 \%)$ \\
\hline \multicolumn{5}{|l|}{ HER2 } \\
\hline$\overline{\mid A^{*}}$ & $0(0 \%)$ & 22 (88.0\%) & $2(8.0 \%)$ & 1 (4.0\%) \\
\hline $\mathrm{IB}^{* *}$ & $4(5.2 \%)$ & $54(70.1 \%)$ & $18(23.4 \%)$ & $1(1.3 \%)$ \\
\hline$\|^{* * * *}$ & $4(3.3 \%)$ & $55(45.1 \%)$ & $61(50.0 \%)$ & $2(1.6 \%)$ \\
\hline\|\|$^{* * * *}$ & $3(6.7 \%)$ & $6(13.3 \%)$ & $36(80.0 \%)$ & $0(0 \%)$ \\
\hline Total & $11(4.1 \%)$ & 137 (50.9\%) & $117(43.5 \%)$ & $4(1.5 \%)$ \\
\hline \multicolumn{5}{|c|}{ Triple negative } \\
\hline$\overline{I A^{*}}$ & $4(23.5 \%)$ & $8(47.1 \%)$ & $4(23.5 \%)$ & 1 (5.9\%) \\
\hline $\mathrm{B}^{* *}$ & $8(14.3 \%)$ & $30(53.6 \%)$ & $14(25.0 \%)$ & $4(7.1 \%)$ \\
\hline$\|^{* * *}$ & $3(4.0 \%)$ & $38(50.7 \%)$ & $32(42.7 \%)$ & $2(2.7 \%)$ \\
\hline\|\|$^{* * * *}$ & $2(15.4 \%)$ & $0(0 \%)$ & $9(69.2 \%)$ & 2 (15.4\%) \\
\hline Total & $17(10.6 \%)$ & $76(47.2 \%)$ & $59(36.6 \%)$ & $9(5.6 \%)$ \\
\hline
\end{tabular}

The second important consideration is about stage. In the current study there is a lower incidence of high-risk nodal disease ( $\mathrm{pN} 2-\mathrm{pN} 3)$, which decreased from 17.1\% of NORA to $9.9 \%$ of NEMESI study $(p=0.0001)$. This is probably due to more extensive use of breast cancer screening in recent years in Italy. Probably, for the same reason, pT1 increased from $59.7 \%$ of patients in NORA to $67.0 \%$ of NEMESI ( $\mathrm{p}<0.0001$ ).

These demographical, pathological and biological characteristics seem to be in contrast with the high rate of adjuvant chemotherapy prescription. $57.8 \%$ of the population study received adjuvant chemotherapy. Population study was composed by $85 \%$ of endocrine responsive breast cancers, $84 \%$ of HER2 negative, $61 \%$ of nodenegative and 2 of 3 cases with tumor diameter inferior to $2 \mathrm{~cm}, 22.3 \% \leq 1 \mathrm{~cm}$. International guidelines recommend the use of adjuvant chemotherapy on the basis of all prognostic and predictive parameters but in general it is not recommended for patients with pT1, pN0, ERpositive, low proliferation index, HER2 negative breast cancer. We noted that, overall, 38.1\% of luminal A population was treated with adjuvant chemotherapy: $6 \%$ in stage IA, $22.6 \%$ in stage IB, $56.2 \%$ in stage II, $81.0 \%$ in stage III. It means that $33.8 \%$ of luminal A with low (pT1 pN0) or intermediate recurrence risk (pT2/pT3 pN0 or pN1) was treated with adjuvant chemotherapy. $25 \%$ of entire study population receiving adjuvant chemotherapy was luminal A with low or intermediate risk recurrence. This fact underlines an overtreatment and over prescription with adjuvant chemotherapy. In fact, luminal A is recognized as the less sensitive breast cancer subtype to adjuvant chemotherapy. The cut-off for luminal A was set to a proliferative index $\leq 20 \%$. As indicated by Cheang et al., ki67 of $14 \%$ is considered the proliferation index able to distinguish luminal A versus luminal B [18]. Modifying the cut-off value of proliferative index from $20 \%$ to $14 \%$ in order to distinguish between luminal A versus luminal B we obtained similar data: $29.5 \%$ of luminal A with stage IA, IB, II was treated with adjuvant chemotherapy and OR for the use of adjuvant chemotherapy in luminal B versus luminal A was $1.95(\mathrm{OR}=1.40-2.72)$ similar to that reported in Table 4.

NEMESI study identified tumor and patient characteristics that were important determinants in the decision to prescribe a chemotherapy regimen and the choice of chemotherapy type. Whereas adjuvant chemotherapy prescription by Italian oncologists is influenced by prognostic and predictive parameters, type of adjuvant chemotherapy is significantly influenced by age, menopausal status and above all by the risk of recurrence (pT and $\mathrm{pN}$ ), but not by biological predictive factors. In fact, prescription of CMF-like regimen decreases with increasing $\mathrm{pT}$ and $\mathrm{pN}$ in favor of the use of anthracyclines plus taxanes. In particular, as previously reported, considering small tumors pT1a and pT1b compared to larger tumors, CMF-like prescription decreases from $14.2 \%$ to $9.9 \%$ of pT1c and $6.9 \%$ of pT2, pT3, pT4b [19]. More recurrence risk is, more is the use of the most effective regimen anthracyclines plus taxanes. The choice for anthracyclines plus taxanes should be considered not on the basis of $\mathrm{pT}$ and $\mathrm{pN}$ but on the basis of sensitiveness to chemotherapy. As indicated by St. Gallen guidelines, luminal B, HER2 and triple negative should receive both anthracyclines and taxanes, which, on the contrary, are treated with this regimen in only $37.0 \%, 43.5 \%$ and $36.6 \%$ of cases, respectively.

Another important issue is about older age and prescription of the type of adjuvant chemotherapy. In fact, administration of CMF-like regimen was more frequently used for women aged $\geq 70$ (27.0\%) than for women under 70 (9.1\%) and, as previously reported, this percentage increased until $50 \%$ considering only pT1a and pT1b tumors [19]. This choice is in contrast with data from randomized trials conducted in elderly women in whom CMF-like was demonstrated to be more toxic and less feasible compared to anthracyclines, like AC regimen [20]. 
On multivariate analysis, the only biological parameter little influencing the choice of chemotherapy type is HER2. In HER2-positive breast cancer patients, anthracyclines use increased; this is probably also influenced by the results of a meta-analysis by Gennari et al. [21]. There was an overall increase in anthracyclines use in HER2-positive versus HER2-negative patients (absolute increase: 9.4\%); however, while anthracyclines alone were prescribed equally between HER2-positive and HER2negative patients, there was higher use of anthracyclines plus taxanes in HER2-positive versus HER2-negative patients (absolute increase: 6.9\%). This data is also consistent with a meta-analysis conducted by De Laurentiis et al. [22] which demonstrated that chemotherapy containing anthracyclines plus taxanes is more effective than anthracyclines alone in HER2-positive breast cancer.

Finally, patients treated with chemotherapy included schedules with CMF-like regimen or AC/EC for four cycles. Recently, EBCTCG demonstrated that these regimens remain suboptimal schedules in terms of efficacy. We know from EBCTCG metanalysis that more effective chemotherapy regimens included anthracyclines with doxorubicin with a dose of at least $60 \mathrm{mg} / \mathrm{m}^{2}$ per cycle or epirubicin with a dose of at least $90 \mathrm{mg} / \mathrm{m}^{2}$ per cycle with cumulative dose of more than $240 \mathrm{mg} / \mathrm{m}^{2}$ and $360 \mathrm{mg} / \mathrm{m}^{2}$, respectively, or regimens including anthracyclines plus taxanes [23]. Overall, $25.3 \%$ of population study was treated with CMF-like or AC/EC four cycles and $12 \%$ with FEC for 6 cycles but with suboptimal epirubicin dose per cycle $\left(75 \mathrm{mg} / \mathrm{m}^{2}\right)$. These data were confirmed also for particular sensitive disease to chemotherapy, HER2-positive and triple negative, in which suboptimal chemotherapy with CMF-like or AC/ EC for 4 cycles was prescribed in $24.2 \%$ and $22.2 \%$, respectively. FEC 6 cycles with epirubicin $75 \mathrm{mg} / \mathrm{m}^{2}$ was adopted in $12.3 \%$ and $11.8 \%$, respectively.

\section{Conclusions}

This observational study showed a possible $25 \%$ of over prescription of adjuvant chemotherapy for early breast cancer, particularly referred to luminal A biological subtype. Prognostic parameters (pT and $\mathrm{pN}$ ) and only marginally HER2 were the principal determinants for the prescription of the type of chemotherapy, with the use of more effective regimen (anthracyclines and taxanes) with increasing risk recurrence and HER2-positive. Suboptimal chemotherapy regimens (CMF-like or AC/E or FEC with suboptimal epirubicin dose) were adopted in at least one third of highly chemosensitive disease (HER2-positve and triple negative).

\section{Competing interest}

The authors have no conflicts of interest that are directly relevant to the content of this article, including any financial, personal or other relationship with other people or organizations within that could inappropriately influence the results of this work. Davide Dondi is a full-time employee of Sanofi-Aventis Italy. The manuscript was prepared independently from Sanofi-Aventis Italy.

\section{Acknowledgements}

All authors thank Francesco Baretta (Quintiles) for statistical analysis of this study. This study was sponsored by Sanofi-Aventis, Italy.

\section{Author details}

${ }^{1}$ Ospedale Sacro Cuore Don Calabria, Negrar, Verona, Italy. ${ }^{2}$ Ospedale Civile, Centro Oncologico, Trieste, Italy. IRST, Meldola Forli, Italy. ${ }^{4}$ IRRCS A.O.U. San Martino IST, Genoa, Italy. ${ }^{5}$ Istituto Nazionale Tumori, Naples, Italy. ${ }^{6} \mathrm{AORN}$ Cardarelli, Naples, Italy. ${ }^{7}$ A.O. Policlinico G. Martino, Messina, Italy. ${ }^{8}$ A.O. Carlo Poma, Mantova, Italy. ${ }^{9}$ Ospedale Unico Versilia, Lido di Camaiore, Lucca, Italy. ${ }^{10}$ A.O. S. Andrea, Rome, Italy. ${ }^{11}$ Ospedale Santa Maria della Misericordia, Perugia, Italy. ${ }^{12}$ Ospedale A. Cardarelli, Campobasso, Italy. ${ }^{13}$ IRCCS Casa Sollievo della Sofferenza, San Giovanni Rotondo, Foggia, Italy. ${ }^{14}$ IRCCS Oncologico, Bari, Italy. ${ }^{15}$ Sanofi-Aventis, Milan, Italy. ${ }^{16}$ Oncology Department, Ospedale Sacro Cuore Don Calabria Via Don A. Sempreboni 5, 37024 Negrar, Verona, Italy.

\section{Authors' contributions}

Matteo Clavarezza was responsible for manuscript writing. All authors read and approved the final paper.

Received: 28 November 2011 Accepted: 6 June 2012

Published: 6 June 2012

\section{References}

1. The Nordcan Project; 2012. http://www-dep.iarc.fr/nordcan/English/frame. asp. Last update: 8 March.

2. SEER, Surveillance Epidemiology and End Results; 2011. http://seer.cancer.gov/ statfacts/html/breast.html\#incidence-mortality. Last update: November 10.

3. Cancer Research UK; 2011. http://info.cancerresearchuk.org/cancerstats/ types/breast/incidence/ Last update: July 18.

4. Ravdin PM, Cronin KA, Howlader N, Berg CD, Chebowski RT, Feuer EJ, Edwards BK, Berry DA: The decrease in breast-cancer incidence in 2003 in the United States. N Engl J Med 2007, 356:1670-1674.

5. Rossouw JE, Anderson GL, Prentice RL, LaCroix AZ, Kooperberg C, Stefanick ML, Jackson RD, Beresford SA, Howard BV, Johnson KC, Kotchen JM, Ockene J: Writing Group for the Women's Health Initiative Investigators: Risks and benefits of estrogen plus progestin in healthy postmenopausal women: principal results from the Women's Health Initiative randomized controlled trial. JAMA 2002, 288:321-333.

6. Crocetti E, Buzzoni C, Falcini F, Cortesi L, De Lisi V, Ferretti S, Tumino R, Russo A, Paci E: Disentangling the roles of mammographic screening and HRT in recent breast cancer trends in Italy by analyses based on calendar and time screening activation. Breast J 2010, 16:350-355.

7. Buiatti E, Barchielli A, Bartolacci S, Bucchi L, De LV, Federico M, Ferretti S, Paci E, Vettorazzi M, Zanetti R, SCREENREG Working Group: Stage-specific incidence of breast cancer before the beginning of organized screening programs in Italy. Cancer Causes Control 2002, 13:65-71.

8. Paci E, Coviello E, Miccinesi G, Puliti D, Cortesi L, De Lisi V, Ferretti S, Mangone L, Perlangeli V, Ponti A, Ravaioli A, de' Bianchi PS, Segnan N, Stracci F, Tumino R, Zarcone M, Zorzi M, Zappa M, IMPACT Working Group: Evaluation of service mammography screening impact in Italy. The contribution of hazard analysis. Eur J Cancer 2008, 44:858-865.

9. AIRTUM: I numeri del cancro in Italia: Intermedia Editore; 2011.

10. Puliti D, Miccinesi G, Collina N, Puliti D, Miccinesi G, Collina N, De Lisi V, Federico M, Ferretti S, Finarelli AC, Foca F, Mangone L, Naldoni C, Petrella M, Ponti A, Segnan N, Sigona A, Zarcone M, Zorzi M, Zappa M, Paci E, IMPACT Working Group: Effectiveness of service screening: a case-control study to access breast cancer mortality reduction. Br J Cancer 2008, 99:423-427.

11. Berry DA, Cronin KA, Plevritis SK, Fryback DG, Clarke L, Zelen M, Mandelblatt JS, Yakovlev AY, Habbema JD, Feuer EJ: Cancer Intervention and Surveillance Modeling Network (CISNET) Collaborators. Effect of screening and adjuvant therapy on mortality from breast cancer. N Engl J Med 2005, 353:1784-1792

12. National Comprehensive Cancer Network: NCCN clinical practice guidelines in oncology:: Breast cancer; 2012. Version 1.2012:: 2012. Retrieved March 18. 
13. National Cancer Institute: Breast Cancer Treatment. 2012. PDQ. 2012. Retrieved March 18

14. Goldhirsch A, Wood WC, Coates AS, Gelber RD, Thurlimann B, Senn HJ: Panel Members: Strategies for subtypes-dealing with the diversity of breast cancer: highlights of the St. Gallen international expert consensus on the primary therapy of early breast cancer 2011. Ann Oncol 2011, 22:1736-1747.

15. Associazione Italiana di Oncologia Medica (AIOM): // Libro Bianco dell'Oncologia Italiana. thirdth edition. 2006 [Italian].

16. Greene FL, Page DL, Fleming ID: AJCC Cancer Staging Manual. 6th edition, New York: Springer; 2002

17. Cazzaniga ME, Mustacchi G, Pronzato P, De Matteis A, Di Costanzo F, Floriani I: NORA Study Group. Adjuvant systemic treatment of early breast cancer: the NORA study. Ann Oncol 2006, 17:1386-1392.

18. Cheang MC, Chia SK, Voduc D, Gao D, Leung S, Snider J, Watson M Davies S, Bernard PS, Parker JS, Perou CM, Ellis MJ, Nielsen TO: Ki67 index, HER2 status and prognosis of patients with luminal B breast cancer. J Natl Cancer Inst 2009, 101:736-750.

19. Gori S, Clavarezza M, Siena S, Foglietta J, Tarenzi E, Giordano M, Molino A, Graiff C, Fusco V, Alabiso O, Baldini E, Gamucci T, Altavilla G, Dondi D, Venturini M: Adjuvant chemotherapy of $\mathrm{pT} 1 \mathrm{a}$ and $\mathrm{pT} 1 \mathrm{~b}$ breast carcinoma: results from the NEMESI study. BMC Cancer 2012, 12:158.

20. Muss HB, Berry DA, Cirrincione $C T$, Theodoulou M, Mauer AM, Kornblith AB, Partridge AH, Dressler LG, Cohen HJ, Becker HP, Kartchescke PA, Wheeler JD, Perez EA, Wolff AC, Gralow JR, Burstein HJ, Mahmood AA, Magrinat G, Parker BA, Hart RD, Grenier D, Norton L, Hudis CA, Winer EPfor the CALGB Investigators: Adjuvant chemotherapy in older women with early-stage breast cancer. N Eng J Med 2009, 360:2055-2065.

21. Gennari A, Sormani MP, Pronzato P, Puntoni M, Colozza M, Pfeffer U, Bruzzi P: HER2 status and efficacy of adjuvant anthracyclines in early breast cancer: a pooled analysis of randomized trials. J Natl Cancer Inst 2008, 100:14-20.

22. De Laurentiis $M$, Cancello G: D Agostino D, Giuliano M, Giordano A, Montagna E, Lauria R, Forestieri V, Esposito A, Silvestro L, Pennacchio R, Criscitiello C, Montanino A, Limite G, Bianco AR, De Placido S: Taxanebased combinations as adjuvant chemotherapy of early breast cancer: a meta-analysis of randomized trials. J Clin Oncol 2008, 26:44-53.

23. Early Breast Cancer Trialists' Collaborative Group: Comparison between different polychemotherapy regimens for early breast cancer: meta-analyses of long-term outcome among 100000 women in 123 randomized trials. Lancet 2012, 379:432-444.

doi:10.1186/1471-2407-12-216

Cite this article as: Clavarezza et al.: Biological characterization and selection criteria of adjuvant chemotherapy for early breast cancer: experience from the Italian observational NEMESI study. BMC Cancer 2012 12:216

\section{Submit your next manuscript to BioMed Central and take full advantage of:}

- Convenient online submission

- Thorough peer review

- No space constraints or color figure charges

- Immediate publication on acceptance

- Inclusion in PubMed, CAS, Scopus and Google Scholar

- Research which is freely available for redistribution 